\title{
Magnetodeformation effects in a crystal lattice
}

\author{
B.A.Lukiyanets ${ }^{1}$, R.M.Peleshchak ${ }^{2}$ \\ 1 State University "Lvivs'ka Politechnika", \\ 12 Bandera Str. 290646 Lviv, Ukraine \\ 2 I.Franko Pedagogical University, \\ 34 I.Franko Str., 293720 Drohobych, Lviv region, Ukraine
}

Received March 11, 1998

\begin{abstract}
A crystal with a local plane defect in the external magnetic field $B$ oriented along the plane is investigated. Within the framework of the variational method a qualitative analysis of the degree of deformation depending on $B$ is carried out. It is shown that an increase of $B$ entails a more localized lattice distortion and its increase.
\end{abstract}

Key words: crystal, plane defect, magnetic field, electron-deformation interaction

PACS: $62.20 . \mathrm{Fe}, 71.45 . \mathrm{Gm}$.

Real crystals are those which have impurities or various defects of a crystalline lattice. Induced by them distortions give rise to redistribution of electrons in a crystal and, as a result, to renormalization of these distortions $[1,2]$.

In the given paper the relative deformation $\rho(r)=\left(\delta V_{k}-\delta V\right) / \delta V=\operatorname{Sp} \xi$ $\left(\delta V, \delta V_{k}\right.$ are volumes of the primitive unit cells with or without the presence of deformation respectively; $\xi$ is a tensor of deformation) of a crystal with a plane defect (e.g.,a twinning plane) in the external magnetic field oriented along the plane defect is analyzed.

Let a plane defect in a crystalline lattice be with a normal along OX. It creates a force action which is described by the potential

$$
U(r) \equiv U(x)=U_{0} \exp \left(-\alpha x^{2}\right)
$$

$\left(U_{0}, \alpha\right.$ are constants), i.e. such an action has a one-dimensional character.

The energy of the system of a crystal and an electron in the state $\psi(r)$ interacting with the relative deformation $\rho(r)$ in a continuum approximation may be 
written in the form [3]:

$$
E\{\psi, \rho\}=\int \mathrm{d}^{3} r\left[\frac{h^{2}}{2 m^{*}}|\nabla \psi(r)|^{2}-\sigma \rho(r)|\psi(r)|^{2}+\frac{1}{2} \beta \rho^{2}(r)+U(r)|\psi(r)|^{2}\right],
$$

where the first term in the integrand is the kinetic energy of an electron, the second is its interaction with the deformation of the lattice, the third is the energy of an interaction of an electron with a local deformation (with a plane defect in the case under consideration). It is supposed that the crystal is isotropic ( $m^{*}$ is a scalar).

Let the external magnetic field be imposed on a crystal along the plane defect (say along OZ). Consideration of the field in (1) is reduced to a formal replacement $p \rightarrow(p-e A / c)$ [3], where $p=-\mathrm{i} \hbar \nabla$ is a momentum operator and $A$ is a vector potential. Then (2) takes the form:

$$
\begin{aligned}
E\{\psi, \rho\}=\int \mathrm{d}^{3} r & {\left[\frac{1}{2 m^{*}}\left|\left(p-\frac{e}{c} A\right) \psi(r)\right|^{2}-\sigma \rho(r)|\psi(r)|^{2}\right.} \\
+ & \left.\frac{1}{2} \beta \rho^{2}(r)+U(r)|\psi(r)|^{2}\right] .
\end{aligned}
$$

From a variation of $E\{\psi, \rho\}$ with respect to $\rho(r)$ at fixed $\psi(r)$

$$
\rho(r)=\frac{\sigma}{\beta}|\psi(r)|^{2} .
$$

It is seen that taking into account (4), $E\{\psi, \rho\}$ becomes a functional with respect to $\psi(r)$ only.

Let the vector potential $A=(0, B x, 0)$ ( $B$ is a magnetic field). Then,

$$
\begin{aligned}
E\{\psi\}=\int \mathrm{d}^{3} r & \left\{\frac{\hbar^{2}}{2 m}\left[\left|p_{x} \psi(r)\right|^{2}+\left|\left(p_{y}-\frac{e}{c} x B\right) \psi(r)\right|^{2}+\left|p_{z} \psi(r)\right|^{2}\right]\right. \\
& \left.-\frac{\sigma}{2 \rho}|\psi(r)|^{4}+U(r)|\psi(r)|^{2}\right\} .
\end{aligned}
$$

We use a variational method for the estimation of the magnetodeformation effect in our problem. Since we are interested in $\rho(r)$, according to (4), the wave function must be found. In order to solve the problem by the variational method it is necessary to clarify this statement. It is known $[4,5]$ that the variational method does not allow a control of the wave function: even if its use leads to a sufficiently accurate eigenvalue, it is impossible to estimate the difference between the wave function obtained by the variational method and the exact one. But this deficiency is not so important for using a probe (obtained by the variational method) function for the study of the changes of $\rho(r)$ depending on the parameters of the problem (magnetic field, electron-deformation interaction), but important for the calculation of its absolute value. This very approach is realized below.

Take the probe function in the form

$$
\psi(r)=\exp \left(\mathrm{i} k_{z} z\right) \exp \left(-\mu\left(x^{2}+y^{2}\right)\right)
$$


i.e. with a single parameter $\mu$.

Constant $C$ in (6) may be obtained from the normalization condition:

$$
C=\frac{\sqrt{\mu}}{\pi} .
$$

In (6) it is taken into account that the applied magnetic field and the lattice distortion (1) do not change the electron motion along $\mathrm{OZ}$ and it is described by a plane wave.

Using (6), the minimum of the functional of energy is easily found by the variational method. Substitution of (6) in (5) and integration yield:

$$
E\{\psi\} \equiv E\{\mu\}=\left(\frac{\hbar^{2}}{m}-\frac{\sigma^{2}}{4 \beta \pi^{2}}\right) \mu+\frac{1}{4 \mu}\left(\frac{e B}{c}\right)^{2}+U_{0} \sqrt{\frac{2 \mu}{2 \mu+\alpha}} .
$$

Consider a qualitative conclusion about the extremum (minimum) $E\{\psi\}$. In the limit case $U_{0}=0$, the minimum of $E\{\psi\}$ is realized at

$$
\mu=\frac{(e B / c)}{2 \sqrt{\hbar^{2} / 2 m-\sigma^{2} / 4 \beta \pi^{2}}} .
$$

Using (8) in the probe function (6) and its relation with $\rho(r)(4)$, allows us to state:

- an increase of the magnetic field leads to localization of the distortion with its simultaneous increase;

- for crystals with larger elastic constants or with a smaller electron-deformation interaction the relative deformation is more delocalized and has a smaller value.

To estimate the role of the local deformation $\sim U_{0}$ in the problem, let us consider $\mu \gg \alpha$. We expand the last term in (7) in a power series in $\alpha$ :

$$
\sqrt{\frac{2 \mu}{2 \mu+\alpha}}=\sqrt{2 \mu}\left(\frac{1}{\sqrt{2 \mu}}-\left.\frac{1}{2(\sqrt{2 \mu+\alpha})^{3}}\right|_{\alpha=0} \alpha+\ldots\right) \sim 1-\frac{\alpha}{4 \mu} .
$$

Then, the extremum of $E\{\mu\}$ is realized at

$$
\mu=\frac{1}{2} \sqrt{\frac{(e B / c)^{2}-U_{o} \alpha}{\hbar^{2} / m-\sigma^{2} / 4 \beta \pi^{2}}}
$$

Thus, taking into account the interaction energy of an electron with the local deformation $\sim U_{0}$ leads to delocalization of a relative deformation of the crystal at $U_{0}>0$ and to a more marked localization at $U_{0}<0$.

Note that the analysis (within the framework of the quasiclassic approximation) is justifiable for the $\mu a^{2} \leqslant 0.01$ case [3] ( $a$ is some characteristic length of the problem, e.g., a lattice parameter). 


\title{
References
}

1. Stasyuk I.V., Peleshchak R.M. Filling of the electron states and the metal lattice deformation in the vicinity of the border between the regions with different mechanical strains. // Ukr. fiz. zhurn., 1991, vol. 36, No 11, p. 1744-1749 (in Ukrainian).

2. Peleshchak R.M., Lukiyanets B.A. The electron redistribution in the vicinity of the core of the linear dislocation. // Pisma v ZhTF, 1998, vol. 21, No 2, p. 32-36 (in Russian).

3. Davydov A.S. Theory of Solid State. M., Nauka, 1976 (in Russian).

4. Madelung E. Mathematical technique of physics. M., Nauka,1968 (in russian).

5. Messia A. Quantum mechanics. M., Nauka, 1979 (in Russian).

\section{Магнітодеформаційні ефекти в кристалічній гратці}

\author{
Б.А.Лукіянець ${ }^{1}$, Р.М.Пелещак ${ }^{2}$ \\ 1 Державний університет "Львівська Політехніка", \\ 290646 Львів, вул.С.Бандери, 12 \\ 2 Дрогобицький педагогічний інститут ім.І.Франка, \\ 293720 Дрогобич Львівської обл., вул.І.Франка, 34
}

Отримано 11 березня 1998 р.

Розглядається кристал з локальним плоским дефектом, поміщений в зовнішне магнітне поле, орієнтоване вздовж дефекту. В рамках варіаційного принципу проведено якісний аналіз ступеня деформації в залежності від величини поля $B$. Показано, що зростання $B$ приводить до більш локалізованого спотворення гратки з одночасним його зростанням.

Ключові слова: кристал, плоский дефект, магнітне поле, електрон-деформаційна взаємодія

PACS: $62.20 . \mathrm{Fe}, 71.45 . \mathrm{Gm}$ 